Article

\title{
An Eight-Channel C-Band Demux Based on Multicore Photonic Crystal Fiber
}

\author{
Dror Malka * and Gilad Katz \\ Faculty of Engineering, Holon Institute of Technology (HIT), Holon 5810201, Israel; giladka@hit.ac.il \\ * Correspondence: drorm@hit.ac.il
}

Received: 29 August 2018; Accepted: 15 October 2018; Published: 17 October 2018

\begin{abstract}
A novel eight-channel demux device based on multicore photonic crystal fiber (PCF) structures that operate in the C-band range (1530-1565 nm) has been demonstrated. The PCF demux design is based on replacing some air-hole areas with lithium niobate and silicon nitride materials over the PCF axis alongside with the appropriate optimizations of the PCF structure. The beam propagation method (BPM) combined with Matlab codes was used to model the demux device and optimize the geometrical parameters of the PCF structure. The simulation results showed that the eight-channel demux can be demultiplexing after light propagation of $5 \mathrm{~cm}$ with a large bandwidth $(4.03-4.69 \mathrm{~nm})$ and cross-talk ( -16.88 to $-15.93 \mathrm{~dB})$. Thus, the proposed device has great potential to be integrated into dense wavelength division multiplexing (DWDM) technology for increasing performances in networking systems.
\end{abstract}

Keywords: photonic crystal fiber; demultiplexer; dense wavelength division multiplexing

\section{Introduction}

Dense wavelength division multiplexing (DWDM) is a system [1,2] that is used to integrate information from different sources over one fiber, while each source carried on its own divided light wavelength at the same time. DWDM has the ability to divide sources up into 80 ports, and allow more information to be multiplexed into a light-stream that is transferred on one fiber. Demux is an essential device in the DWDM system, and its main functionality is to divide signals from one input port into multiple ports. The demux device has several advantages such as a low bit error rate [3], a high data rate, a large bandwidth, low cross-talk [4], and less propagation delay. Therefore, researchers have shown the potential of designing demux-based waveguide techniques such as silicon photonics [5], Y-branch [6], multimode interference (MMI) [7-9], Mach-Zehnder interferometers [10,11], MMI in slot waveguide structures [12-14], etc.

Photonic crystal fiber (PCF) is a powerful waveguide that is based on a microstructured arrangement of materials of different refractive indexes [15]. The background material is usually pure silica, and the low-index regions are air-holes that are located along the fiber length. Several works have demonstrated the great potential of using PCF structures in comparison to conventional fibers [16-18]. The main benefit of designing a demux device based on a PCF structure is its ability to integrate different materials that have a high difference in their refractive index values. This is because the light guiding mechanism in PCF is based on the bandgap and modified total internal reflection (MTIR). Another advance is the ability to achieve a lower coupling length, especially in the case of closer coupled ports (cores) [19].

Several techniques have demonstrated how it is possible to couple light between closer coupled ports (cores) in a PCF structure through methods such as changing the PCF index profile by replacing some air-hole regions with pure silica along the fiber length $[19,20]$ and using different air-hole sizes in the PCF structure [21-24]. 
The C-band range is set from $1530 \mathrm{~nm}$ to $1565 \mathrm{~nm}$ in the wavelength, and it is the most efficient and useful range in the optical communication field [14]. The advance of the C-band is the ability to transmit data with a high bitrate over a long distance since the C-band supports DWDM and optical amplifier fiber technologies [25].

In this work, we demonstrated a $1 \times 8$ wavelength demux in a PCF structure that split eight wavelengths in the C-band range. The operating wavelengths are between 1530-1565 $\mathrm{nm}$ with a spacing of $5 \mathrm{~nm}$ between two wavelengths. The light coupling between the closer coupled cores was obtained by replacing some air-hole areas with lithium niobate $\left(\mathrm{LiNbO}_{3}\right)$ and silicon nitride $\left(\mathrm{Si}_{3} \mathrm{~N}_{4}\right)$ materials along the fiber length.

Numerical investigations were carried out on the locations of the $\mathrm{LiNbO}_{3}$ and $\mathrm{Si}_{3} \mathrm{~N}_{4}$ s layers and the key geometrical parameters of the multicore PCF structure to obtain high efficiency demultiplexing between the operating wavelengths. The demux PCF structure was analyzed and simulated using a beam propagation method (BPM) and Matlab codes. This device can be useful to increase the data bitrate in the C-band using a DWDM system.

To the best of our knowledge, this paper is the first to study the controlling of light propagation direction by integrating $\mathrm{LiNbO}_{3}$ and $\mathrm{Si}_{3} \mathrm{~N}_{4}$ rods over a multicore PCF structure. This new study was utilized to design a new demultiplexer based on a multicore PCF structure. Thus, the novelty is that the demultiplexer operated within the multicore PCF structure without using additional optical components. This can lead to a new DWDM technique that can be utilized to reduce the costs and size of the optical communication system.

\section{Materials and Methods}

Figure 1a-c show the full refractive index profile structure of the demux PCF design on the $X Z$ plane $(y=0 \mathrm{~cm}), X Y$ plane $(z=0 \mathrm{~cm})$, and $X Y$ plane $(z=5 \mathrm{~cm})$, respectively. In these figures, the background material is pure silica, and it is marked in a light blue color; the air-hole areas are marked in a purple color, the $\mathrm{LiNbO}_{3}$ areas are marked in a red color, and the $\mathrm{Si}_{3} \mathrm{~N}_{4}$ areas are marked in a yellow color. The geometrical parameters of the PCF structure are $d, \Lambda$ (pitch), and z. In Figure $1 \mathrm{a}, \mathrm{d}$ represents the hole diameter of the air-holes, pitch represents the distance between two air-holes, and $\mathrm{z}$ represents the light propagation axis.

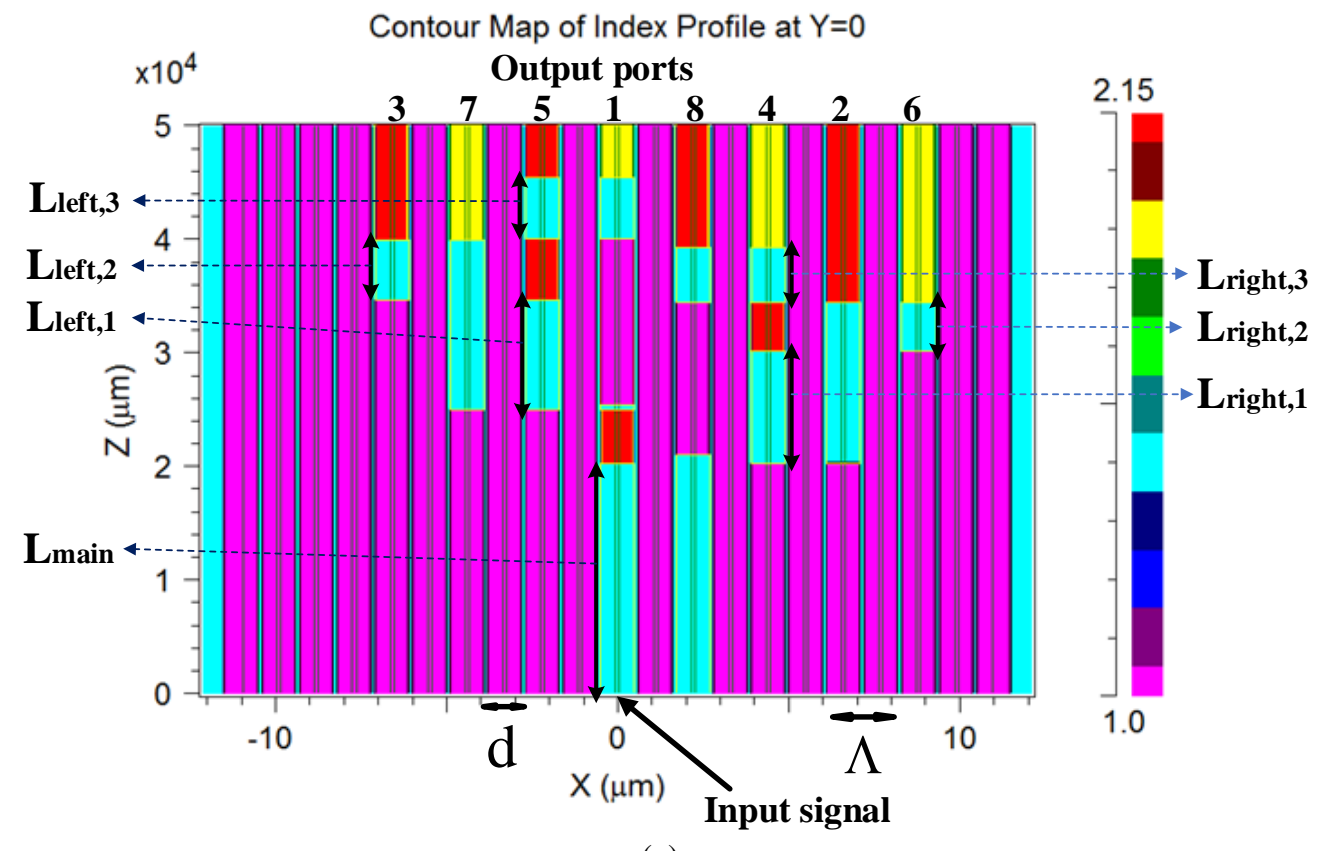

(a)

Figure 1. Cont. 


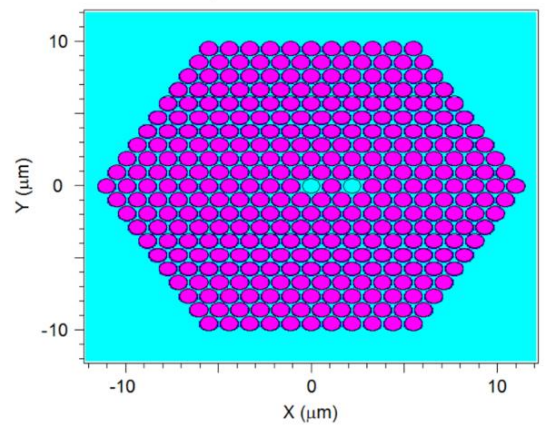

(b)

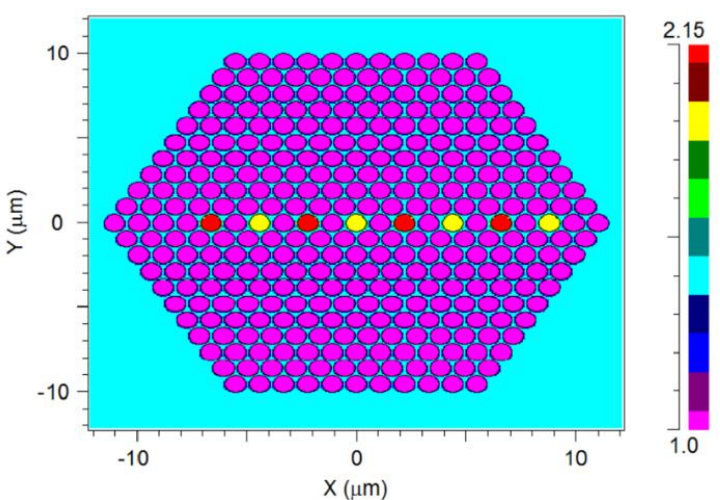

(c)

Figure 1. Refractive index profile of the $1 \times 8$ wavelength demux: (a) $X Z$ plane at $y=0 \mathrm{~cm}$. (b) $X Y$ plane at $\mathrm{z}=0 \mathrm{~cm}$. (c) $X Y$ plane at $\mathrm{z}=5 \mathrm{~cm}$.

The principle work of the PCF demux device is based on light confinement inside the channel (core) and controlling the light coupling length size between two closer ports (cores). These effects can be obtained by replacing some air-hole regions with a high-index material along the fiber length. Furthermore, the coupling length value can be shifted by changing the operating wavelength. Thus, the suitable coupling length value between two closer ports can be found by optimized the PCF geometrical parameters $(\mathrm{z}, \Lambda, \mathrm{d})$ and the materials' layer locations over the light propagation axis $(\mathrm{z})$.

In our design, the light-guiding mechanism is based on the bandgap and the MTIR, which means that light can be coupled between two closer ports that have the same refractive index value (light blue color areas in Figure 1a), and a strong light confinement can be obtained by a port that has a high index value (red and yellow areas in Figure 1a).

It can be noticed from Figure 1a that the areas in which light can be coupled between closer silica (light blue color) ports (cores) are located as follows: port 1 and port 8 over the Z-axis range of $0-2.03 \mathrm{~cm}\left(\mathrm{~L}_{\text {main }}\right)$, port 8 and port 4 over the $Z$-axis ranges of $2.03-2.1 \mathrm{~cm}$ and $3.445-3.93 \mathrm{~cm}\left(\mathrm{~L}_{\text {right }, 3}\right)$, port 1 and port 5 over the $Z$-axis range of $2.5-2.545 \mathrm{~cm}$ and $4-4.545 \mathrm{~cm}\left(\mathrm{~L}_{\text {left, } 3}\right)$, port 4 and port 2 over $Z$-axis range of $2.03-3.01 \mathrm{~cm}\left(\mathrm{~L}_{\text {right }, 1}\right)$, port 5 and port 7 over the $Z$-axis range of $2.5-3.46 \mathrm{~cm}\left(\mathrm{~L}_{\text {left, } 1}\right)$, port 2 and port 6 over the Z-axis range of $3.01-3.44 \mathrm{~cm}\left(\mathrm{~L}_{\text {right, } 2}\right)$, port 3 and port 7 over the $Z$-axis range of $3.47-3.995 \mathrm{~cm}\left(\mathrm{~L}_{\text {left,2}}\right)$. In addition, it can be noticed that each port at the output has a light confinement area, as shown in Figure 1a. Figure $1 b, c$ show the input port at $z=0$ (port 1 ) and eight output ports at $\mathrm{z}=5 \mathrm{~cm}$ (red and yellow colors).

Table 1 shows the refractive index material values for the C-band range [26-28], and it is important to mention that the $\mathrm{Si}_{3} \mathrm{~N}_{4}$ and $\mathrm{LiNbO}_{3}$ materials have a very low absorption in this range. Another advance to use these materials is that light cannot be coupled between closer $\mathrm{Si}_{3} \mathrm{~N}_{4}$ and $\mathrm{LiNbO}_{3}$ layers, because they have a small difference in the index value, as shown in Table 1.

Table 1. The multicore photonic crystal fiber (PCF) materials' reflective index values.

\begin{tabular}{ccccccccc}
\hline$\lambda_{\mathbf{m}}(\mathbf{n m})$ & $\mathbf{1 5 3 0}$ & $\mathbf{1 5 3 5}$ & $\mathbf{1 5 4 0}$ & $\mathbf{1 5 4 5}$ & $\mathbf{1 5 5 0}$ & $\mathbf{1 5 5 5}$ & $\mathbf{1 5 6 0}$ & $\mathbf{1 5 6 5}$ \\
\hline $\mathrm{n}_{\mathrm{Si}_{3} \mathrm{~N}_{4}}$ & 1.9968 & 1.9967 & 1.9966 & 1.9964 & 1.9963 & 1.9961 & 1.996 & 1.9959 \\
$\mathrm{n}_{\mathrm{Silica}}$ & 1.4443 & 1.4442 & 1.4441 & 1.4441 & 1.444 & 1.444 & 1.4439 & 1.4438 \\
$\mathrm{n}_{\mathrm{LiNbO}_{3}}$ & 2.1481 & 2.148 & 2.1478 & 2.1477 & 2.1476 & 2.1474 & 2.1473 & 2.1471 \\
\hline
\end{tabular}

The $\mathrm{Si}_{3} \mathrm{~N}_{4}$ and the $\mathrm{LiNbO}_{3}$ layers were used to enable a strong light confinement inside the port that ensures that light cannot be coupled to other closer ports. In the proposed design, there are 11 layers that function as follows: eight output lines (four $\mathrm{LiNbO}_{3}$ layers for ports 2, 3, 5, and 8, and four $\mathrm{Si}_{3} \mathrm{~N}_{4}$ layers for ports 1, 4, 6, and 7) and three selected lines in a similar way to the classical definitions of the digital $1 \times 8$ demultiplexer. 
The three $\mathrm{LiNbO}_{3}$ layers were used to function as the selected waveguide switch that controls the light propagation direction along the fiber length. The first selected switch is located at the Z-axis range between $2.03-2.5 \mathrm{~cm}$, and can demultiplex the light propagation between ports 1, 5, 7, and 3, and ports $8,4,2$, and 6 . The second selected switch is located at the Z-axis range between $3.01-3.445 \mathrm{~cm}$, and can demultiplex the light propagation between ports 8 and 4 , and ports 2 and 6 . The third selected switch is located at the Z-axis range between $3.46-4 \mathrm{~cm}$, and can demultiplex the light propagation between ports 3 and 7 and ports 5 and 1 .

It is important to emphasize that the coupling length of the resonated light between two closer ports is dependent on the key geometrical parameters $(d, \Lambda)$ and the operating wavelength. Thus, the coupling length can be found using the equation below [29,30]:

$$
\mathrm{L}^{\lambda} \text { Coupling }=\frac{\pi}{\mathrm{k}_{0}\left(\mathrm{n}_{\text {symmetric }}(\mathrm{d}, \Lambda, \lambda)-\mathrm{n}_{\text {anti-symmertric }}(\mathrm{d}, \Lambda, \lambda)\right)}
$$

where $\mathrm{k}_{0}$ is the free-space wave vector, $\lambda$ is the operating wavelength, and $\mathrm{n}_{\text {anti-symmetric }}$ and $\mathrm{n}_{\text {symmetric }}$ are the anti-symmetric and symmetric effective refractive index, respectively.

It is worth mentioning that the coupling length is periodical due to the oscillation between two closer ports.

The conditions for divide eight different wavelengths in the proposed design are given by:

$$
\begin{aligned}
& \mathrm{L}_{\text {main }} \approx \mathrm{p}_{1} \mathrm{~L}_{\text {Coupling }}^{\lambda_{1}, \lambda_{3}, \lambda_{5}, \lambda_{7}}=\left(\mathrm{p}_{1}+\mathrm{q}_{1}\right) \mathrm{L}_{\text {Coupling }}^{\lambda_{2}, \lambda_{4}, \lambda_{6}, \lambda_{8}} \\
& \mathrm{~L}_{\text {right }, 1} \approx \mathrm{p}_{2} \mathrm{~L}_{\text {Coupling }}^{\lambda_{8,}, \lambda_{4}}=\left(\mathrm{p}_{2}+\mathrm{q}_{2}\right) \mathrm{L}_{\text {Coupling }}^{\lambda_{2}, \lambda_{6}} \\
& \mathrm{~L}_{\text {left }, 1} \approx \mathrm{p}_{3} \mathrm{~L}_{\text {Coupling }}^{\lambda_{3}, \lambda_{7}}=\left(\mathrm{p}_{3}+\mathrm{q}_{3}\right) \mathrm{L}_{\text {Coupling }}^{\lambda_{5}, \lambda_{1}} \\
& \mathrm{~L}_{\text {right }, 2} \approx \mathrm{p}_{4} \mathrm{~L}_{\text {Coupling }}^{\lambda_{2}}=\left(\mathrm{p}_{4}+\mathrm{q}_{4}\right) \mathrm{L}_{\text {Coupling }}^{\lambda_{6}} \\
& \mathrm{~L}_{\text {left }, 2} \approx \mathrm{p}_{5} \mathrm{~L}_{\text {Coupling }}^{\lambda_{3}}=\left(\mathrm{p}_{5}+\mathrm{q}_{5}\right) \mathrm{L}_{\text {Coupling }}^{\lambda_{7}} \\
& \mathrm{~L}_{\text {right }, 3} \approx \mathrm{p}_{6} \mathrm{~L}_{\text {Coupling }}^{\lambda_{8}}=\left(\mathrm{p}_{6}+\mathrm{q}_{6}\right) \mathrm{L}_{\text {Coupling }}^{\lambda_{4}} \\
& \mathrm{~L}_{\text {left }, 3} \approx \mathrm{p}_{7} \mathrm{~L}_{\text {Coupling }}^{\lambda_{5}}=\left(\mathrm{p}_{7}+\mathrm{q}_{7}\right) \mathrm{L}_{\text {Coupling }}^{\lambda_{1}}
\end{aligned}
$$

where $\mathrm{L}_{\text {main }}$ is the fiber length located between core 1 and core 8 (silica areas), $\mathrm{L}_{\text {righ, } 1}$ is the fiber length located between core 2 and core 4 (silica areas), $\mathrm{L}_{\mathrm{left}, 1}$ is the fiber length located between core 7 and core 5 (silica areas), $\mathrm{L}_{\text {righ,2 }}$ is the fiber length located between core 2 and core 6 (silica areas), $\mathrm{L}_{\text {left, } 2}$ is the fiber length located between core 3 and core 7 (silica areas), $\mathrm{L}_{\text {righ, } 3}$ is the fiber length located between core 8 and core 4 (silica areas), $\mathrm{L}_{\mathrm{left}, 3}$ is the fiber length located between core 5 and core 1 (silica areas), $\mathrm{p}_{1 / 2 / 3 / 4 / 5 / 6 / 7}$ is a natural number, and $\mathrm{q}_{1 / 2 / 3 / 4 / 5 / 6 / 7}$ is an odd number.

For analyzing the performances of our proposed $1 \times 8$ wavelength demultiplexer multicore PCF, cross-talk (Equation (3)) and loss (Equation (4)) were calculated to observe the ratio between a desirable and undesirable wavelength in a given port and power losses, respectively.

$$
\mathrm{C} . \mathrm{T}_{\mathrm{n}}=\frac{1}{3} \sum_{\mathrm{m}=1}^{4} 10 \log \left(\frac{\mathrm{P}_{\mathrm{m}}}{\mathrm{P}_{\mathrm{n}}}\right)
$$

where $\mathrm{P}_{\mathrm{n}}$ is the power transmission for the suitable port, and $\mathrm{P}_{\mathrm{m}}$ is the interference power transmission from the other ports. The insertion loss is given by:

$$
\operatorname{Loss}_{\mathrm{dB}}=-10 \log \left(\frac{\mathrm{P}_{\text {out }}}{\mathrm{P}_{\text {in }}}\right)
$$

where $\mathrm{P}_{\text {out }}$ is the power at the output port, and $\mathrm{P}_{\text {in }}$ is the power in the input port 1. 


\section{Results}

The $1 \times 8$ PCF wavelength demultiplexer structure was simulated using an RSoft Photonics CAD suite software, which is based on the BPM. Figure 2 shows the optimal geometrical parameters $(d / \Lambda)$ of the $1 \times 8$ wavelength demultiplexer multicore PCF structure for the operating wavelengths. It can be noticed from Figure 3 that the optimal value is 0.85 for the operating wavelengths, and the values of $\mathrm{d}$ and $\Lambda$ are $0.97 \mu \mathrm{m}$ and $1.14 \mu \mathrm{m}$.

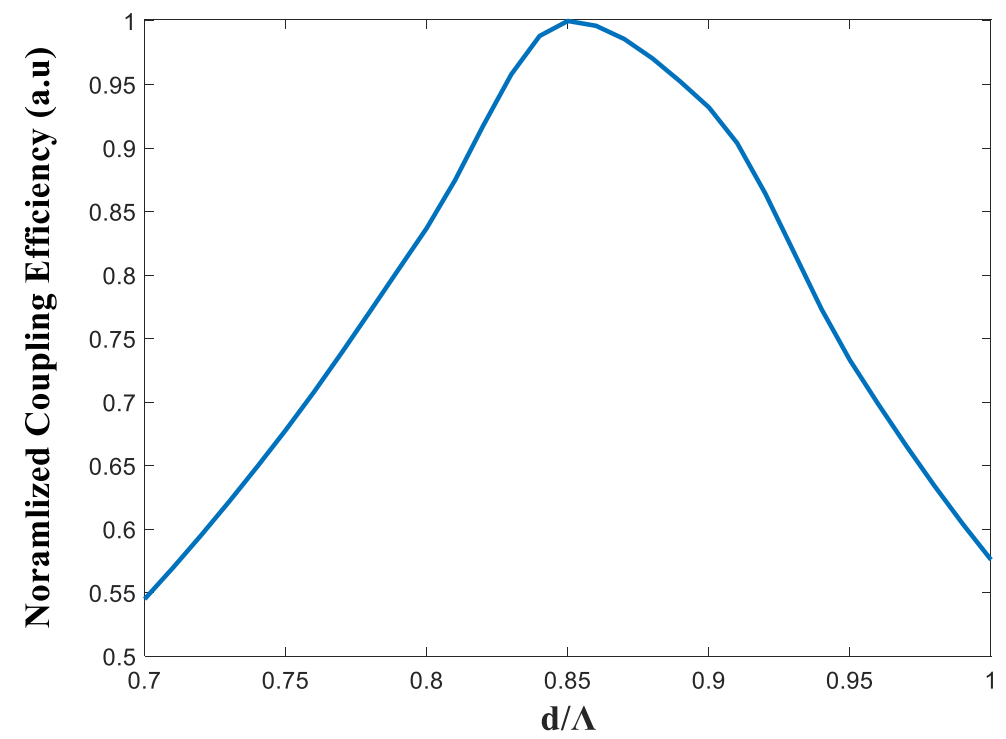

Figure 2. Normalized coupling efficiency as a function of the geometrical parameters of the multicore photonic crystal fiber $(\mathrm{PCF})(\mathrm{d} / \Lambda)$ for the operating wavelengths.

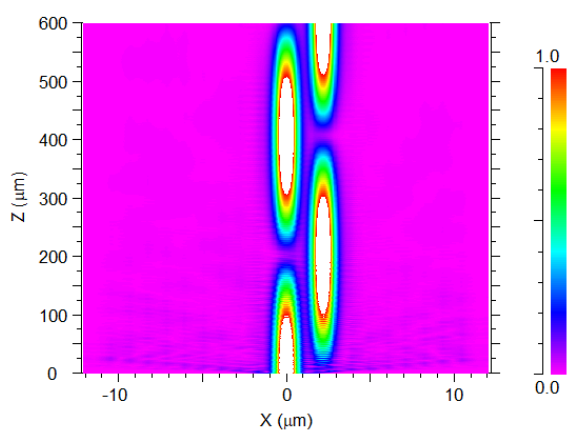

(a)

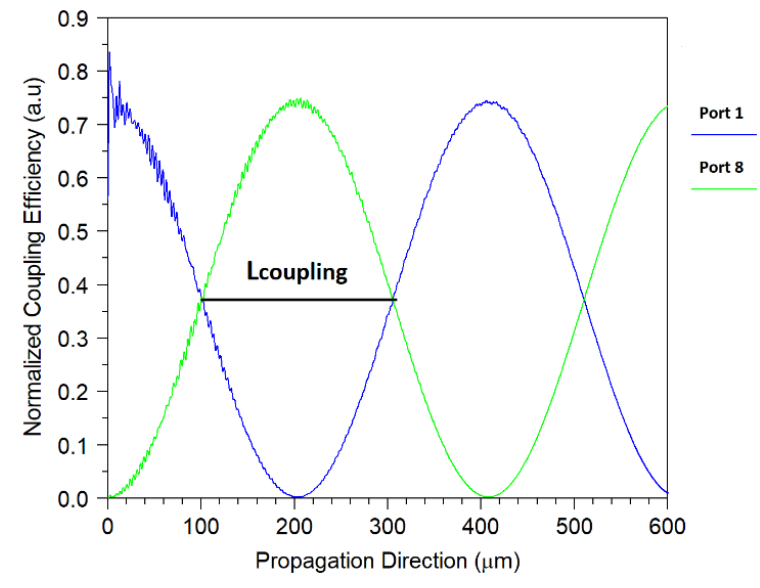

(b)

Figure 3. Energy transfer between core 1 and core 8 for the $1565-n m$ wavelength. (a). Intensity profile. (b). Normalized coupling efficiency as a function of the propagation direction.

The coupling length size for each operating wavelength was calculated by simulating the transfer energy between two closer silica cores. Figure 3a,b show the full transfer energy between port 1 and port 8 at the Z-range from $0-600 \mu \mathrm{m}$ for the $1565-\mathrm{nm}$ operated wavelength. From Figure $3 \mathrm{~b}$, it can be noticed that the coupling length value is $203.41 \mu \mathrm{m}$. The same simulation was done for each of the operating wavelengths, and the values of the coupling length were found as shown in Table 2. 
Table 2. The coupling length values.

\begin{tabular}{ccccccccc}
\hline$\lambda_{\mathrm{m}}(\mathrm{nm})$ & $\mathbf{1 5 3 0}\left(\boldsymbol{\lambda}_{1}\right)$ & $\mathbf{1 5 3 5}\left(\boldsymbol{\lambda}_{2}\right)$ & $\mathbf{1 5 4 0}\left(\boldsymbol{\lambda}_{3}\right)$ & $\mathbf{1 5 4 5}\left(\lambda_{4}\right)$ & $\mathbf{1 5 5 0}\left(\boldsymbol{\lambda}_{5}\right)$ & $\mathbf{1 5 5 5}\left(\boldsymbol{\lambda}_{6}\right)$ & $\mathbf{1 5 6 0}\left(\lambda_{7}\right)$ & $\mathbf{1 5 6 5}\left(\boldsymbol{\lambda}_{8}\right)$ \\
\hline $\mathrm{L}_{\text {Coupling }}(\mu \mathrm{m})$ & 230.89 & 225.1 & 222.83 & 219.12 & 214.71 & 211.11 & 208.34 & 203.41 \\
\hline
\end{tabular}

By using the results taken from Table 2 and combining them with Equation (2), the locations and the lengths of the silica rods that are suitable for the $1 \times 8$ wavelength demultiplexer multicore PCF can be found, and their values are: $\mathrm{L}_{\text {main }}=2.03 \mathrm{~cm}, \mathrm{~L}_{\text {right }, 1}=0.98 \mathrm{~cm}, \mathrm{~L}_{\text {left }, 1}=0.96 \mathrm{~cm}, \mathrm{~L}_{\text {right }, 2}=0.43 \mathrm{~cm}$, $\mathrm{L}_{\text {left }, 2}=0.525 \mathrm{~cm}, \mathrm{~L}_{\mathrm{right}, 3}=0.485 \mathrm{~cm}$, and $\mathrm{L}_{\text {left }, 3}=0.545 \mathrm{~cm}$. Using these results along with the optimizations over the multicore PCF length, the locations $(2.03-2.5 \mathrm{~cm}$ at the Z-axis in core 1, $3.01-3.445 \mathrm{~cm}$ at the Z-axis in core 4, and $3.46-4 \mathrm{~cm}$ at the Z-axis in core 5) of the three selected switch $\mathrm{LiNbO}_{3}$ layers were found. In addition, the eight output port layers were optimized in order to obtain a compact $1 \times 8$ demultiplexer, and their locations are found as shown in Figure 1a.

Figure 4a shows the light propagation of the 1530-nm wavelength in the PCF structure, and its optical path can be described as follows: $\mathrm{z}=0-1.9 \mathrm{~cm}$, light coupled between port 1 and port 8; $\mathrm{z}=1.9-2.5 \mathrm{~cm}$, light confined in port $1 ; \mathrm{z}=2.5-2.6 \mathrm{~cm}$, light coupled from port 1 to port $5 ; \mathrm{z}=2.6-3.5 \mathrm{~cm}$, light coupled between port 5 and port $7 ; z=3.5-4 \mathrm{~cm}$, light confined in port $5 ; z=4-4.7 \mathrm{~cm}$, light coupled between port 5 and port 1 ; and $z=4.7-5 \mathrm{~cm}$, light confined in port 1 . Figure $4 \mathrm{~b}$ shows the light propagation of the 1535-nm wavelength in the PCF structure, and its optical path can be described as follows: $\mathrm{z}=0-2 \mathrm{~cm}$, light coupled between port 1 and port $8 ; \mathrm{z}=2-2.15 \mathrm{~cm}$, light coupled from port 8 to port $4 ; z=2.15-3 \mathrm{~cm}$, light coupled between port 4 and port $2 ; z=3-3.5 \mathrm{~cm}$, light coupled between port 2 and port $6 ; z=3.5-5 \mathrm{~cm}$, light confined in port 2 . Figure $4 \mathrm{c}$ shows the light propagation of the 1540-nm wavelength in the PCF structure, and its optical path can be described as follows: $\mathrm{z}=0-1.9 \mathrm{~cm}$, light coupled between port 1 and port $8 ; \mathrm{z}=1.9-2.5 \mathrm{~cm}$, light confined in port 1; $\mathrm{z}=2.5-2.6 \mathrm{~cm}$, light coupled from port 1 to port $5 ; \mathrm{z}=2.6-3.5 \mathrm{~cm}$, light coupled between port 5 and port 7; $z=3.6-4 \mathrm{~cm}$, light coupled between port 3 and port $7 ; z=4-5 \mathrm{~cm}$, light confined in port 3 . Figure $4 \mathrm{~d}$ shows the light propagation of the $1545-\mathrm{nm}$ wavelength in the PCF structure, and its optical path can be described as follows: $\mathrm{z}=0-2 \mathrm{~cm}$, light coupled between port 1 and port $8 ; \mathrm{z}=2-2.15 \mathrm{~cm}$, light coupled from port 8 to port $4 ; z=2.15-3 \mathrm{~cm}$, light coupled between port 4 and port $2 ; z=3-3.5 \mathrm{~cm}$, light confined in port $4 ; \mathrm{z}=3.5-4 \mathrm{~cm}$, light coupled between port 4 and port 8 ; and $\mathrm{z}=4-5 \mathrm{~cm}$, light confined in port 4. Figure 4e shows the light propagation of the 1550-nm wavelength in the PCF structure, and its optical path can be described as follows: $\mathrm{z}=0-1.9 \mathrm{~cm}$, light coupled between port 1 and port $8 ; z=1.9-2.5 \mathrm{~cm}$, light confined in port $1 ; z=2.5-2.6 \mathrm{~cm}$, light coupled from port 1 to port $5 ; z=2.6-3.5 \mathrm{~cm}$, light coupled between port 5 and port $7 ; z=3.5-4 \mathrm{~cm}$, light confined in port $5 ; \mathrm{z}=4-4.7 \mathrm{~cm}$, light coupled between port 5 and port 1 ; and $\mathrm{z}=4.7-5 \mathrm{~cm}$, light confined in port 5 . Figure $4 \mathrm{f}$ shows the light propagation of the 1555-nm wavelength in the PCF structure, and its optical path can be described as follows: $\mathrm{z}=0-2 \mathrm{~cm}$, light coupled between port 1 and port $8 ; \mathrm{z}=2-2.15 \mathrm{~cm}$, light coupled from port 8 to port $4 ; z=2.15-3 \mathrm{~cm}$, light coupled between port 4 and port $2 ; z=3-3.5 \mathrm{~cm}$, light coupled between port 2 and port 6 ; and $\mathrm{z}=3.5-5 \mathrm{~cm}$, light confined in port 6 . Figure $4 \mathrm{~g}$ shows the light propagation of the 1560-nm wavelength in the PCF structure, and its optical path can be described as follows: $\mathrm{z}=0-1.9 \mathrm{~cm}$, light coupled between port 1 and port $8 ; \mathrm{z}=1.9-2.5 \mathrm{~cm}$, light confined in port $1 ; z=2.5-2.6 \mathrm{~cm}$, light coupled from port 1 to port $5 ; \mathrm{z}=2.6-3.5 \mathrm{~cm}$, light coupled between port 5 and port $7 ; z=3.6-4 \mathrm{~cm}$, light coupled between port 3 and port 7 ; and $z=4-5 \mathrm{~cm}$, light confined in port 7. Figure $4 \mathrm{~h}$ shows the light propagation of the $1565-\mathrm{nm}$ wavelength in the PCF structure and its optical path can be described as follows: $\mathrm{z}=0-2 \mathrm{~cm}$, light coupled between port 1 and port 8 ; $\mathrm{z}=2-2.15 \mathrm{~cm}$, light coupled from port 8 to port $4 ; \mathrm{z}=2.15-3 \mathrm{~cm}$, light coupled between port 4 and port $2 ; \mathrm{z}=3-3.5 \mathrm{~cm}$, light confined in port $4 ; \mathrm{z}=3.5-4 \mathrm{~cm}$, light coupled between port 4 and port 8 ; and $\mathrm{z}=4-5 \mathrm{~cm}$, light confined in port 8 . 


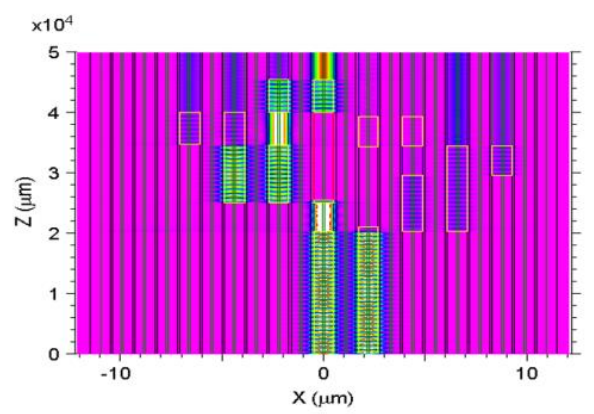

(a)

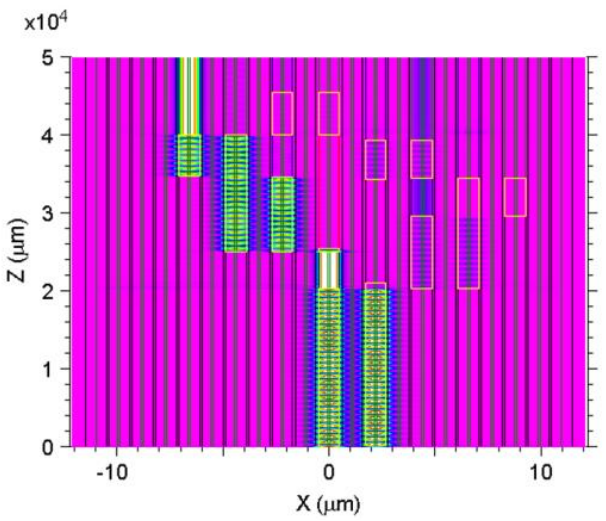

(c)

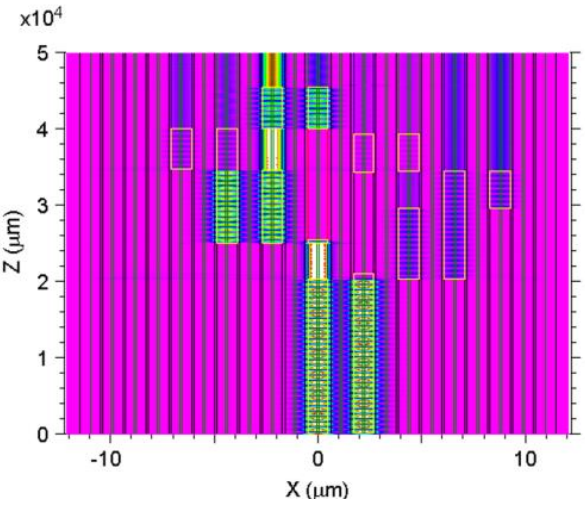

(e)

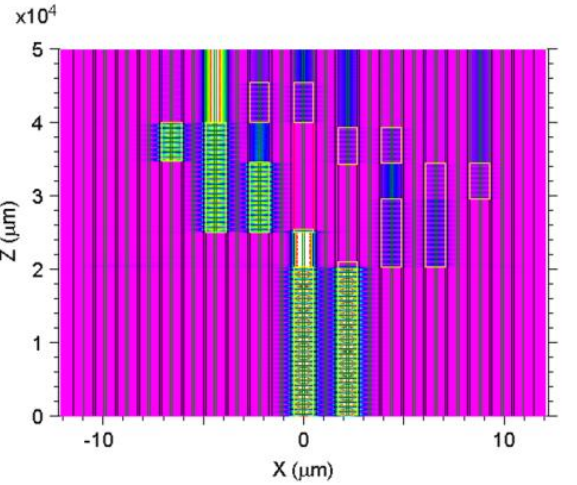

(g)

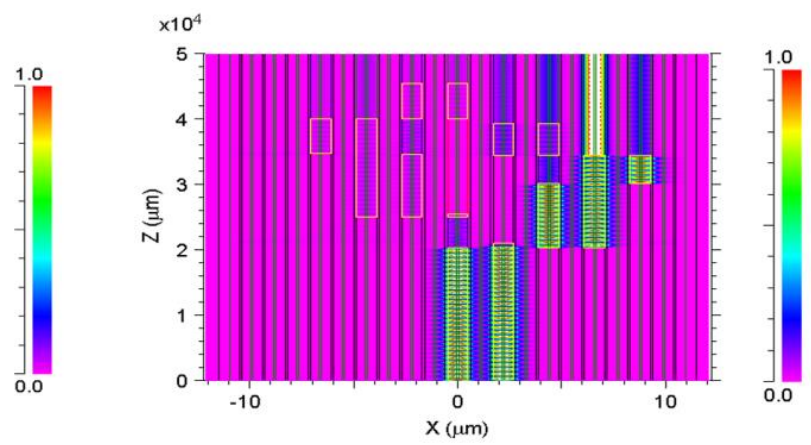

(b)

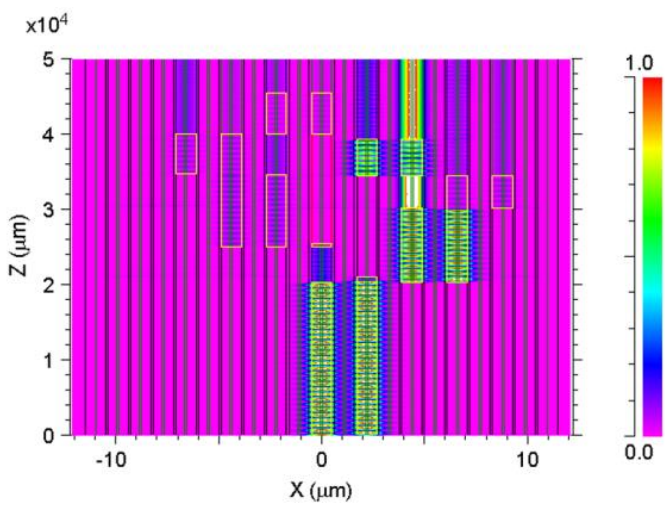

(d)

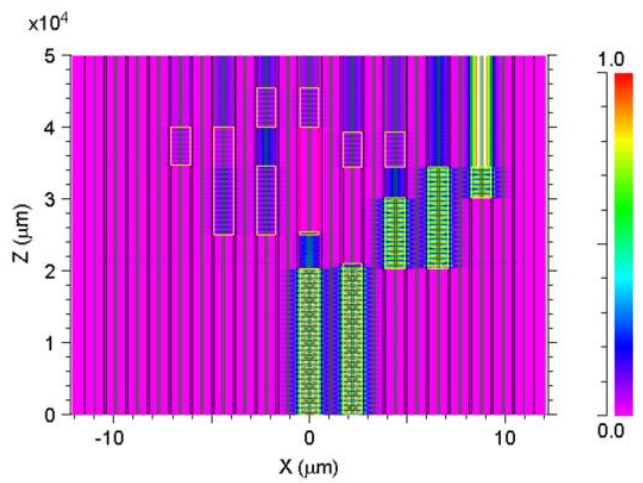

(f)

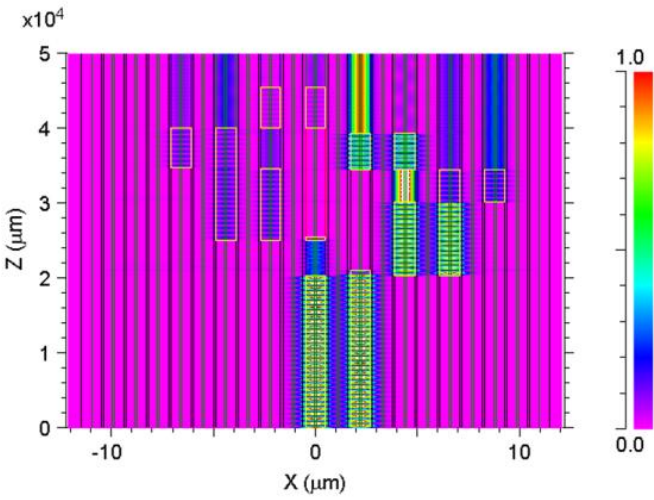

(h)

Figure 4. Intensity profile of the $1 \times 8$ multimode interference (MMI) wavelength demultiplexer: (a) $\lambda_{1}=1530 \mathrm{~nm}$ (port 1). (b) $\lambda_{2}=1535 \mathrm{~nm}$ (port 2). (c) $\lambda_{3}=1540 \mathrm{~nm}$ (port 3). (d) $\lambda_{4}=1545 \mathrm{~nm}$ (port 4). (e). $\lambda_{5}=1550 \mathrm{~nm}$ (port 5). (f) $\lambda_{6}=1555 \mathrm{~nm}$ (port 6). (g) $\lambda_{7}=1560 \mathrm{~nm}$ (port 7). and (h) $\lambda_{8}=1565 \mathrm{~nm}$ (port 8). 
BPM simulations combined with the Matlab script code were performed to determine the $1 \times 8$ wavelength PCF demultiplexer properties. Figure 5 shows the optical bandwidth transmission results for wavelengths around the C-band range (1530-1565 nm).

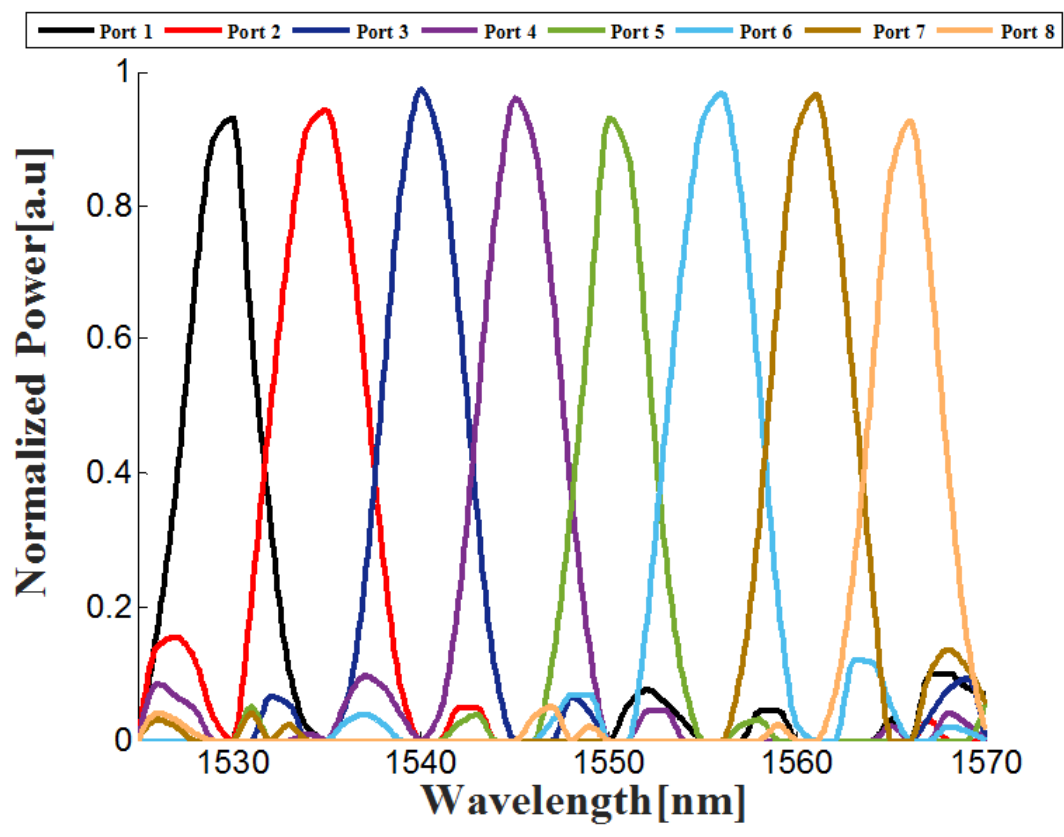

Figure 5. Normalized power as function of the optical signals.

From Figure 5, combined with Equations (3) and (4), the values of the cross-talk, insertion losses and full width maximum (FWHM) can be found. Table 3 shows the values of the cross-talk, bandwidth (FWHM), and loss for each port.

Table 3. Values of the cross-talk, full width maximum (FWHM), and losses for the operating wavelengths.

\begin{tabular}{ccccccccc}
\hline$\lambda_{\mathbf{m}}(\mathbf{n m})$ & $\mathbf{1 5 3 0}$ & $\mathbf{1 5 3 5}$ & $\mathbf{1 5 4 0}$ & $\mathbf{1 5 4 5}$ & $\mathbf{1 5 5 0}$ & $\mathbf{1 5 5 5}$ & $\mathbf{1 5 6 0}$ & $\mathbf{1 5 6 5}$ \\
\hline Port number & 1 & 2 & 3 & 4 & 5 & 6 & 7 & 8 \\
Cross-talk (dB) & -16.65 & -16.73 & -16.88 & -16.81 & -16.6 & -16.32 & -16.08 & -15.93 \\
FWHM (nm) & 4.23 & 4.38 & 4.67 & 4.69 & 4.03 & 4.1 & 4.62 & 4.15 \\
Losses (dB) & 0.31 & 0.26 & 0.2 & 0.18 & 0.55 & 0.31 & 0.45 & 0.69 \\
\hline
\end{tabular}

\section{Conclusions}

This study shows how it is possible to implement the classical $1 \times 8$ demultiplexer that is usually based on seven $1 \times 2$ demultiplexer units in a cascade tree structure, only with one multicore PCF. In addition, this work shows how to control the light propagation direction inside the multicore PCF using the MTIR and bandage mechanism that enables light to be coupled only in the silica areas, and a strong light confinement in the $\mathrm{LiNbO}_{3}$ and $\mathrm{Si}_{3} \mathrm{~N}_{4}$ areas.

By analysis of the numerical results, it is clear that the main benefit is that the multicore PCF was designed without using additional device elements, which are usually required in order for the device to function as a $1 \times 8$ demultiplexer. This benefit can lead to a new design of a compact DWDM system that can be utilized to obtain better performances. However, integrating this type of demultiplexer to the DWDM system will require modifying the mode field diameter (MFD) coming out from the multicore PCF. This is due to the DWDM system usually using silica fibers that have a large MFD compared to the multicore PCF. This issue can be solved by integrated a tapered fiber that can convert the MFD of the $1 \times 8$ wavelength demultiplexer to the MFD of the DWDM system. 
The $1 \times 8$ wavelength demultiplexer multicore PCF can be fabricated using a fiber fabrication facility with hybrid materials. The fabrication process cannot be carried out only by a staking or drawing technique; it also requires a microelectronic technique, such as the lithography technique, that can be used to integrate the $\mathrm{LiNbO}_{3}$ and $\mathrm{Si}_{3} \mathrm{~N}_{4}$ layers over the multicore PCF length.

To conclude, in this work, we have shown that a $1 \times 8$ wavelength demultiplexer can be implemented using a multicore PCF structure with integrated $\mathrm{LiNbO}_{3}$ and $\mathrm{Si}_{3} \mathrm{~N}_{4}$ materials.

The simulation results showed that the operated wavelengths of $1530 \mathrm{~nm}, 1535 \mathrm{~nm}, 1540 \mathrm{~nm}$, $1545 \mathrm{~nm}, 1550 \mathrm{~nm}, 1555 \mathrm{~nm}, 1560 \mathrm{~nm}$, and $1565 \mathrm{~mm}$, with a short spacing of $5 \mathrm{~nm}$ and supporting the whole C-band range, can be separated after a propagation length of $5 \mathrm{~cm}$ with a bandwidth range of $4.02-4.69 \mathrm{~nm}$.

The proposed device has low cross-talk $((-16.88)-(-15.93) \mathrm{dB})$ with an insertion loss of $0.18-0.69 \mathrm{~dB}$.

Thus, this device has the potential to increase the data bitrate in an optical communications system that works on DWDM technology.

This research can be used in future work to design a powerful and new demultiplexer device based on multicore polymer/silica fiber in a very similar way, and with the right materials' modification.

Although only the $1 \times 8$ wavelength demultiplexer configuration is considered in this paper, the demultiplexer can also operate as a multiplexer with a reversed direction of the guided light.

Author Contributions: D.M. envisioned the project. D.M. designed the device and performed simulations with support of G.K. D.M. wrote the manuscript and the reply letter. D.M. made all figures and all authors reviewed the manuscript.

Funding: This research received no external funding.

Conflicts of Interest: The authors declare no conflict of interest.

\section{References}

1. Bogdan, H. DWDM fundamentals, components, and applications. J. Opt. Netw. 2002, 1, 184-185.

2. Gong, J.M.; Zuo, X.; Zhao, Y. The steady SRS analysis theory of DWDM transmission system in single-mode silica fiber. Opt. Commun. 2015, 350, 257-262. [CrossRef]

3. Charlier, J.; Laurent, B.; Berlioz, P.; Perbos, J.L. Multi/demultiplexer and spectral isolator for optical inter-satellites communications. Proc. SPIE Opt. Space Commun. 1989, 54, 1131.

4. Malka, D.; Sintov, Y.; Zalevsky, Z. Design of a $1 \times 4$ silicon-Alumina wavelength demultiplexer based on multimode interference in slot waveguide structures. J. Opt. 2015, 17, 125702-125711. [CrossRef]

5. Dalai, P.K.; Sarkar, P. Analysis of silicon waveguide structure for realization of optical MUX/DEMUX circuit: An application of silicon photonics. Optik 2016, 127, 10569-10574. [CrossRef]

6. Xiang, F.; Lam, Y.G. A TM Y-branch wavelength multi/demultiplexer by K/sup +/and Ag/sup +/ion-exchange for/spl lambda/= 1.31 and 1.55/spl mu/m. J. Light. Technol. 1996, 14, 1690-1694. [CrossRef]

7. Lin, K.C.; Lee, W.Y. Guided-wave 1.30/1.55 $\mu \mathrm{m}$ wavelength division multiplexer based on multimode interference. Electron. Lett. 1996, 32, 1259-1261. [CrossRef]

8. Li, B.; Li, G.; Liu, E.; Jiang, Z.; Qin, J.; Wang, X. Low-loss $1 \times 2$ multimode interference wavelength demultiplexer in silicon-germanium alloy. IEEE Photon. Technol. Lett. 1999, 11, 575-577.

9. Tsao, S.L.; Guo, H.C.; Tsai, C.W. A novel $1 \times 2$ single-mode 1300/1550nm wavelength division multiplexer with output facet-tilted MMI waveguide. Opt. Commun. 2004, 232, 371-379. [CrossRef]

10. Goto, N.; Yip, G.L. Y-branch wavelength multi-demultiplexer for $\lambda=1.30 \mu \mathrm{m}$ and $1.55 \mu \mathrm{m}$. Electron. Lett. 1990, 26, 102-103. [CrossRef]

11. Tervonen, A.; Poyhonen, P.; Honkanen, S.; Tahkokorpi, M. A guided-wave Mach-Zehnderinterferometer structure for wavelength multiplexing. IEEE Photonics Technol. Lett. 1991, 3, 516-518. [CrossRef]

12. Xiao, J.; Liu, X.; Sun, X. Design of an ultracompact MMI wavelength demultiplexer in slot waveguide structures. Opt. Express. 2007, 15, 8300-8308. [CrossRef] [PubMed]

13. Malka, D.; Danan, Y.; Ramon, Y.; Zalevsky, Z. A Photonic $1 \times 4$ power splitter based on multimode interference in silicon-gallium-nitride slot waveguide structures. Materials 2016, 9, 516. [CrossRef] [PubMed] 
14. Zaken, B.B.B.; Zanzury, T.; Malka, D. An 8-Channel Wavelength MMI Demultiplexer in Slot Waveguide Structures. Materials 2016, 9, 881. [CrossRef] [PubMed]

15. Russell, P.S.J. Photonic-crystal fibers. J. Lightw. Technol. 2006, 24, 4729-4749. [CrossRef]

16. Birks, T.A.; Knight, J.C.; Russel, P.S.J. Endlessly single-mode photonic crystal fiber. Opt. Lett. 1997, $22,961-963$. [CrossRef] [PubMed]

17. Knight, J.C.; Broeng, J.; Birks, T.A.; Russel, P.S.J. Photonic band gap guidance in optical fiber. Science 1998, 282, 1476-1478. [CrossRef] [PubMed]

18. Broeng, J.; Mogilevstev, D.; Barkou, S.E.; Bjarklev, A. Photonic crystal fibers: A new class of optical waveguides. Opt. Fiber Technol. 1999, 5, 305-330. [CrossRef]

19. Elbaz, D.; Malka, D.; Zalevsky, Z. Photonic crystal fiber based 1xN intensity and wavelength splitters/couplers. Electromagnetics 2013, 32, 209-220. [CrossRef]

20. Malka, D.; Sintov, Y.; Zalevsky, Z. Fiber-laser monolithic coherent beam combiner based on multicore photonic crystal fiber. Opt. Eng. 2014, 54, 011007. [CrossRef]

21. Koshiba, M. Coupling characteristics of multicore photonic crystal fiber-based $1 \times 4$ power splitters. J. Lightw. Technol. 2009, 27, 2062-2068.

22. Malka, D.; Zalevsky, Z. Multicore photonic crystal fiber based $1 \times 8$ two-dimensional intensity splitters/couplers. Electromagnetics 2013, 33, 413-420. [CrossRef]

23. Malka, D.; Peled, A. Power splitting of $1 \times 16$ in multicore photonic crystal fibers. Appl. Surf. Sci. 2017, 417, 34-39. [CrossRef]

24. Malka, D.; Cohen, E.; Zalevsky, Z. Design of $4 \times 1$ power beam combined based on multicore photonic crystal fiber. Appli. Sci. 2017, 7, 695-699. [CrossRef]

25. Dike, J.N.; Ogbe, D.A. Optimizing the efficiency of fiber-optics technology in telecommunications system. In Proceedings of the IEEE international conference on Emerging $\mathcal{E}$ Sustainable Technologies for powerE ICT in Developing Society; IEEE: Owerri, Nigeria, 2013; pp. 135-142.

26. Tan, C.Z. Determination of refractive index of silica glass for infrared wavelengths by IR spectroscopy. J. Non-Cryst. Solids 1998, 223, 158-163. [CrossRef]

27. Luke, K.; Okawachi, Y.; Lamont, M.R.E.; Gaeta, A.L.; Lipson, M. Broadband mid-infrared frequency comb generation in a $\mathrm{Si}_{3} \mathrm{~N}_{4}$ microresonator. Opt. Lett. 2015, 40, 4823-4826. [CrossRef] [PubMed]

28. Zelmon, D.E.; Small, D.L.; Jundt, D. Infrared corrected Sellmeier coefficients for congruently grown lithium niobate and 5 mol.\% magnesium oxide-doped lithium niobite. J. Opt. Soc. Am. B 1997, 14, 3319-3322. [CrossRef]

29. Shoresh, T.; Katanov, N.; Malka, D. $1 \times 4$ MMI visible light wavelength demultiplexer based on GaN slot waveguide structures. Photonics Nanostruct. Fundam. Appl. 2018, 30, 45-49. [CrossRef]

30. Saitoh, K.; Sato, Y.; Koshiba, M. Coupling characteristics of dual-core photonic crystal fiber couplers. Opt. Express 2003, 11, 3188-3194. [CrossRef] [PubMed] 